\title{
Novel Coronavirus Severe Acute Respiratory Syndrome-Coronavirus 2 (Coronavirus Disease 2019): We Shall Overcome!
}

India is currently in the second stage of the coronavirus disease 2019 (COVID-19) pandemic. It all started in December 2019 when there was a cluster of patients with pneumonia in Wuhan, the capital of Hubei province in China. Investigators found that it was caused by a new strain of coronavirus known as severe acute respiratory syndrome-coronavirus 2 (SARS-CoV-2). It has since been labeled as COVID-19. As of March 19, 2020, 230,588 cases have been reported and 9390 patients have died. In India, 173 patients were diagnosed with COVID-19 with 4 deaths reported. On March 11, 2020, the World Health Organization (WHO) has declared COVID-19 as a pandemic. In this issue of IJMPO, Tsang et al. have appropriately reviewed the current knowledge about symptomatology, rapid diagnosis, and treatment as well as prevention strategies for COVID-19. ${ }^{[1]}$

Here, we will summarize the current understanding and practical information to handle this deadly menace. The COVID-19 is transmissible in a community setting, and clusters of infection can be seen in people who return from countries with high infection. ${ }^{[2]}$

\section{Etiology}

Coronaviruses are a large family of viruses that cause illness ranging from the common cold to more severe diseases such as Middle East respiratory syndrome-CoV and SARS-CoV. SARS-CoV-2 is a single-stranded, RNA virus with a diameter of approximately $60-140 \mathrm{~nm}$. It has a crown-like appearance under an electron microscope and is a Betacoronavirus. It has presumably originated from bats with an initial animal-to-human transmission through an intermediary. Its subsequent spread is human to human, with infected people as the most frequent source of its spread. The incubation time of SARS-CoV-2 is usually 3-7 days but could be up to 2 weeks. COVID-19 epidemic doubled about every 7 days, with each patient transmitting the infection to an additional of 2.2 individuals. ${ }^{[3]}$

\section{Mode of Spread}

The SARS-CoV-2 spreads primarily through air by droplet infection from nose or mouth from an infected person to another, usually within 6 feet. The other mode of spread is by contact when the droplets land on the surfaces and spread if a person touches the surface and then touches the eyes, nose, or mouth. One study has shown that SARS-CoV-2 is stable in aerosols (size $<5 \mu \mathrm{m}$ ) for $3 \mathrm{~h}$, plastic and stainless steel for up to $72 \mathrm{~h}$, copper for $4 \mathrm{~h}$, and cardboard for up to $24 \mathrm{~h} \cdot{ }^{[4]}$ Disinfection practices need to be modified with due consideration to this information. The virus is sensitive to ultraviolet rays, heat, ether, ethanol, chlorine-containing disinfectants, peroxyacetic acid, and chloroform. ${ }^{[3]}$

\section{Symptoms}

The common symptoms are fever, cough, and shortness of breath. Some patients can have rhinitis, sore throat, and diarrhea. Rarely, it can lead to SARS, kidney failure, and death. A study from China among 1099 patients with laboratory-confirmed COVID-19 showed that fever and cough were present in $89 \%$ and $68 \%$, respectively. Lymphocytopenia was seen in $83 \%$ and ground-glass opacity of lung in $56 \%$. Among these patients, $5 \%$ needed intensive care unit (ICU) care, $2.3 \%$ needed invasive mechanical ventilation, and 1.4 had died. ${ }^{[5]}$

\section{High-Risk Patients}

High-risk patients include elderly (>60 years); pregnant women; patients with renal failure, cancer, uncontrolled diabetes or hypertension, chronic obstructive airway disease, and coronary heart disease. A study from China reported that patients with older age, high Sequential Organ Failure Assessment (SOFA) score, and d-dimer $>1 \mu \mathrm{g} / \mathrm{ml}$ had a higher risk of mortality. ${ }^{[6]}$ Another study also showed that older patients with comorbidities and acute respiratory distress syndrome had a high risk of mortality. ${ }^{[7]}$ In contrast to adults, most children with COVID-19 infection have a milder course. ${ }^{[8]}$ Patients on chemotherapy and those who are immunocompromised are susceptible to various infections. There is no sufficient information on SARS$\mathrm{CoV}-2$ infection in cancer patients. Limited evidence suggests that cancer patients, especially elderly, are more prone to contract SARS-CoV-2 infection as well as severe complications (ICU care, invasive ventilation, or death). ${ }^{[9]}$

\section{Testing}

High viral load is seen soon after symptom onset and in the nose than in throat secretions. ${ }^{[10]}$ However, one study has shown that the viral load in asymptomatic patients is as high as in symptomatic patients, leading to transmission by asymptomatic patients. ${ }^{[11]}$ The Centers for Disease Control and Prevention recommends testing with COVID-19 reverse transcription-polymerase chain reaction. The Food and Drug Administration approved rapid point-of-care SARS-Co-V-2 diagnostic test on March 21, 2020, where results are available within an hour. ${ }^{[12]}$ The specimen can be from either upper or lower respiratory tract (sputum, nasopharyngeal swab, oropharyngeal swab, nasal aspirate, and lower respiratory tract aspirate) in patients with suspected COVID-19 infection. Appropriate 
personal protective equipment should be worn during collection and transportation of samples from suspected COVID-19 patients. A false-negative result is possible in the early stage of infection. In addition, there is a rare possibility of a false-positive result. According to Tsang et al., testing the sputum offers speedy diagnosis, is easy, and reduces the risk to health-care workers (HCWs) significantly. ${ }^{[1]}$

\section{Indian Council of Medical Research's Revised Testing Guidelines}

1. All symptomatic patients (fever, cough, or shortness of breath) who have undertaken international travel in the last 14 days

2. All symptomatic patients who have contact with COVID-19 laboratory-confirmed positive cases

3. All symptomatic HCWs

4. All hospitalized patients with severe acute respiratory illness

5. Asymptomatic direct and high-risk contacts of a confirmed case should be tested once between day 5 and day 14 of contact. ${ }^{[13]}$

\section{Imaging}

The most common lung findings on computed tomography scan are bilateral, peripheral, and ill-defined groundglass opacity involving both lower lobes. ${ }^{[14]}$ COVID-19 pneumonia can be seen even in asymptomatic patients and can have rapid evolution from focal unilateral to diffuse bilateral ground-glass lung opacities. ${ }^{[14]}$

\section{Treatment}

Isolation and symptomatic supportive care is the current recommended treatment.

A randomized controlled trial in hospitalized patients with severe COVID-19 $(n=199)$ from China has shown no benefit (clinical improvement, mortality, or reduction in viral RNA load) when treated with antiviral drugs (lopinavir-ritonavir combination) as compared to standardof-care treatment. However, the patients recruited for the study had advanced infection with considerable lung damage. ${ }^{[15]}$ The Union Health Ministry of India currently recommends conditional use of these drugs with informed consent. ${ }^{[16]}$ A preclinical study showed that hydroxychloroquine (HCQ) inhibits COVID-19 by attenuating the inflammatory response. ${ }^{[17]} \mathrm{A}$ nonrandomized open-label study with small sample size $(n=20)$ from France showed that COVID-19-infected patients had reduction in viral load when treated with HCQ and azithromycin. However, this study has been criticized for significant limitations including small sample size and inadequate testing of viral load in the controls. ${ }^{[18]}$ A human monoclonal antibody that blocks SARS-CoV-2 is under evaluation. ${ }^{[19]}$

\section{Prognosis}

Nearly $80 \%$ of infections with COVID-19 are mild and recover within weeks. About 5\% need ICU care with a mortality rate of $1 \%-2 \% .^{[5]}$

\section{Prevention and Control}

To date, there is no proven vaccine to prevent infection with COVID-19. Social distancing is recommended to decrease contact between infected and noninfected people and is currently the most effective public health preventive measure. ${ }^{[20]}$ A mathematical modeling study has suggested that contact tracing and case isolation can help to control the COVID-19 within 3 months. ${ }^{[21]}$ There is currently no evidence that traditional medications control or cure the disease.

\section{Suspected Contact with Coronavirus Disease 2019 Patients}

- Home quarantine should be done for a duration of 14 days in case of close contact with a confirmed case of COVID-19

- Clean and disinfect frequently touched surfaces in the quarantined person's room (e.g. bed frames and tables) daily with $1 \%$ sodium hypochlorite solution

- Clean and disinfect toilet surfaces daily with regular household bleach solution/phenolic disinfectants

- Clean the clothes and other linen used by the person separately using common household detergent and dry.

\section{World Health Organization's Recommendation}

- The WHO recommends "Test, Test, Test" to increase testing in all suspected COVID-19 infections so that patients diagnosed with COVID-19 and their contact can be quarantined or treated if symptomatic. This may help to contain the epidemic rapidly. ${ }^{[22]}$

\section{Do's}

- Increase the awareness of COVID-19 infection without increasing fear

- In case of any symptoms such as fever, cough, or shortness of breath, contact your local health-care authorities

- Cover your nose and mouth with a tissue while coughing and sneezing and throw the tissue into a closed bin immediately

- Prefer social distancing and stay at home in a wellventilated room 
- Wash hands frequently and thoroughly with soap and water for at least $20 \mathrm{~s}$. If soap and water is not available, use alcohol-based hand rub

- Stay $1 \mathrm{~m}$ away from sick people

- Wear N95 mask if you have symptoms (fever, cough, and shortness of breath), when caring for a suspected/ proven COVID-19 patient, or attending to any patient with respiratory symptoms

- Use hand sanitizers after using biometric attendance

- Use hand sanitizers after touching or discarding a mask.

\section{Don'ts}

- Do not touch your eyes, nose, or mouth

- Avoid touching mask while using it

- Do not leave mask hanging from the neck

- Do not use the mask after $6 \mathrm{~h}$ of use or after it becomes wet

- Never reuse disposable masks

- Avoid shaking hands or hugging

- Avoid visiting crowded places or social/religious gathering

- Avoid public transportation

- Limit contact with pets and animals

- Do not share personal household items such as glasses, cups, plates, towels, or bedding with other people in your home.

\section{Padmaj Kulkarni', Manikandan Dhanushkodi ${ }^{2}$}

${ }^{1}$ Department of Medical Oncology, Deenanath Mangeshkar Hospital, Pune, Maharashtra, India, ${ }^{2}$ Department of Medical Oncology, Cancer Institute (WIA), Chennai, Tamil Nadu, India

Address for correspondence: Dr. Padmaj Kulkarni,
Deenanath Mangeshkar Hospital, Pune - 411 004, Maharashtra, India E-mail: padmaj.kulkarni@gmail.com

Submitted: 20-Mar-20 Accepted in Revised Form: 22-Mar-2020 Published: 29-Mar-2020

\section{References}

1. Tsang J, Bajpai J. Novel Coronavirus Infection - Knowns and Unknowns with Particular Reference to Oncology - Combating against COVID-19 with "COVID". Indian J Med Paediatr Oncol 2020. DOI: 10.4103/ijmpo.ijmpo_95_20.

2. Pung R, Chiew CJ, Young BE, Chin S, Chen MI, Clapham HE, et al. Investigation of three clusters of COVID-19 in Singapore: Implications for surveillance and response measures. Lancet 2020. pii: S0140-6736(20)30528-6. doi: 10.1016/S01406736(20)30528-6. [Epub ahead of print].

3. Cascella M, Rajnik M, Cuomo A, Dulebohn SC, Di Napoli R. Features, evaluation and treatment coronavirus (COVID-19). In: StatPearls. Florida: StatPearls Publishing; 2020.

4. van Doremalen N, Bushmaker T, Morris DH, Holbrook MG, Gamble A, Williamson BN, et al. Aerosol and Surface Stability of SARS-CoV-2 as Compared with SARS-CoV-1. N Engl J Med 2020. doi: 10.1056/NEJMc2004973. [Epub ahead of print].

5. Guan WJ, Ni ZY, Hu Y, Liang WH, Ou CQ, He JX, et al.; China Medical Treatment Expert Group for Covid-19. Clinical characteristics of coronavirus disease 2019 in China. New Engl J Med 2020. doi: 10.1056/NEJMoa2002032. [Epub ahead of print].

6. Zhou F, Yu T, Du R, Fan G, Liu Y, Liu Z, et al. Clinical course and risk factors for mortality of adult inpatients with COVID-19 in Wuhan, China: A retrospective cohort study. Lancet 2020. pii: S0140-6736(20)30566-3. doi: 10.1016/S0140-6736(20)30566-3. [Epub ahead of print].

7. Yang X, Yu Y, Xu J, Shu H, Xia J, Liu H, et al. Clinical course and outcomes of critically ill patients with SARS-CoV-2 pneumonia in Wuhan, China: A single-centered, retrospective, observational study. Lancet Respir Med 2020. pii: S22132600(20)30079-5. doi: 10.1016/S2213-2600(20)30079-5. [Epub ahead of print].

8. Lu X, Zhang L, Du H, Zhang J, Li YY, Qu J, et al. SARSCoV-2 Infection in Children. N Engl J Med. 2020. doi: 10.1056/ NEJMc2005073. [Epub ahead of print].

9. Liang W, Guan W, Chen R, Wang W, Li J, Xu K, et al. Cancer patients in SARS-CoV-2 infection: A nationwide analysis in China. Lancet Oncol 2020;21:335-7.

10. Zou L, Ruan F, Huang M, Liang L, Huang H, Hong Z, et al. SARS-CoV-2 viral load in upper respiratory specimens of infected patients. N Engl J Med 2020;382:1177-9.

11. Rothe C, Schunk M, Sothmann P, Bretzel G, Froeschl G, Wallrauch C, et al. Transmission of 2019-nCoV infection from an asymptomatic contact in Germany. N Engl J Med 2020;382:970-1.

12. Coronavirus (COVID-19) Update: FDA Issues first Emergency Use Authorization for Point of Care Diagnostic. Available from: https://www.fda.gov/news-events/press-announcements/ coronavirus-covid-19-update-fda-issues-first-emergencyuse-authorization-point-care-diagnostic. [Last accessed on 2020 Mar 20].

13. Indian Council of Medical Research (ICMR) - Revised strategy of COVID-19 testing in India. Available from: https://www. mohfw.gov.in/pdf/ICMRrevisedtestingstrategyforCOVID.pdf. [Last accessed on 2020 Mar 22].

14. Shi $\mathrm{H}$, Han $\mathrm{X}$, Jiang $\mathrm{N}$, Cao $\mathrm{Y}$, Alwalid $\mathrm{O}, \mathrm{Gu} \mathrm{J}$, et al. Radiological findings from 81 patients with COVID-19 pneumonia in Wuhan, China: A descriptive study. Lancet Infect Dis 2020. pii: S1473-3099(20)30086-4. doi: 10.1016/S14733099(20)30086-4. [Epub ahead of print].

15. Cao B, Wang Y, Wen D, Liu W, Wang J, Fan G, et al. A trial of lopinavir-ritonavir in adults hospitalized with severe Covid-19. N Engl J Med 2020. doi: 10.1056/NEJMoa2001282. [Epub ahead of print].

16. Guidelines on Clinical Management of COVID 19. Available from: https://www.mohfw.gov.in/pdf/ GuidelinesonClinicalManagementofCOVID1912020.pdf. [Last accessed on 2020 Mar 20].

17. Liu J, Cao R, Xu M, Wang X, Zhang $\mathrm{H}$, $\mathrm{Hu} \mathrm{H}$, et al. Hydroxychloroquine, a less toxic derivative of chloroquine, is effective in inhibiting SARS-CoV-2 infection in vitro. Cell Discov 2020;6:16. 
18. Hydroxychloroquine and Azithromycin as a Treatment of COVID-19: Results of an Openlabel Non-Randomized Clinical Trial. Available from: https:/www.mediterranee-infection.com/ wp-content/uploads/2020/03/Hydroxychloroquine_final_DOI_ IJAA.pdf. [Last accessed on 2020 Mar 22].

19. Wang C, Li W, Drabek D, Okba NM, van Haperen R. A human monoclonal antibody blocking SARS-CoV-2 infection. bioRxiv 2020.03.11.987958; 2020. [doi:10.1101/2020.03.11.9 87958].

20. Advisory on Social Distancing Measure in View of Spread of COVID-19 Disease. Available from: https://www.mohfw.gov.in/ pdf/SocialDistancingAdvisorybyMOHFW.pdf. [Last accessed on 2020 Mar 20].

21. Hellewell J, Abbott S, Gimma A, Bosse NI, Jarvis CI, Russell TW, et al. Feasibility of controlling COVID-19 outbreaks by isolation of cases and contacts. Lancet Glob Health 2020;8:e488-96.

22. Tondo L. Scientists say mass tests in Italian town have halted Covid-19 there. Guardian 2020.
This is an open access journal, and articles are distributed under the terms of the Creative Commons Attribution-NonCommercial-ShareAlike 4.0 License, which allows others to remix, tweak, and build upon the work non-commercially, as long as appropriate credit is given and the new creations are licensed under the identical terms.

\begin{tabular}{|l|l|}
\hline \multicolumn{2}{|c|}{ Access this article online } \\
\hline Quick Response Code: & Website: \\
& www.ijmpo.org \\
\cline { 2 - 2 } & DOI: \\
\hline
\end{tabular}

How to cite this article: Kulkarni P, Dhanushkodi M. Novel Coronavirus Severe Acute Respiratory Syndrome-Coronavirus 2 (Coronavirus Disease 2019): We Shall Overcome! Indian J Med Paediatr Oncol 2020;41:110-3. 